\title{
Comparison of Online Learning Behaviors in School vs. at Home in Terms of Age and Gender Based on Log File Analysis
}

\author{
Galit Ben-Zadok \\ Tel-Aviv University and \\ The Center for Educational \\ Technology (CET), \\ Tel Aviv, Israel
}

galitb@cet.ac.il

\author{
Moshe Leiba and Rafi Nachmias \\ School of Education, \\ Tel Aviv, Israel
}

moshelei@post.tau.ac.il

nachmias@post.tau.ac.il

\begin{abstract}
The research objectives of this study are: (a) to compare learning behaviors in an online science learning environment - in school vs. at home; and (b) to explore the existence of some behavioral differences, in school and at home, in terms of age and gender. The actions of 1,179 elementary school students in an online science learning environment were documented in a log file and statistically analyzed. Results suggest that students who learn at home tend to spend more time learning; they learn at a slower pace and score higher on a test than students who learn in school. However, no significant differences were found between home and school in terms of the amount of completed activities, the rate of simulation use, and the sequence of learning. Comparison between age groups indicates that younger students tend to learn for more time, at a slower pace, and complete fewer activities than older students. Comparison between genders, on the other hand, reflects similar learning behaviors for boys and girls. The results also suggest that neither age nor gender affect the differences found between school and home behaviors. Our conclusions indicate that extending teaching time to the home by means of online learning environments is possible and worthwhile, regardless of age or gender. Nevertheless, it should be noticed that in some cases more learning time is necessary for young students in online assignments.
\end{abstract}

Keywords: online learning, individual differences, elementary education; evaluation methodologies, log file's analysis.

\section{Introduction}

Material published as part of this publication, either on-line or in print, is copyrighted by the Informing Science Institute. Permission to make digital or paper copy of part or all of these works for personal or classroom use is granted without fee provided that the copies are not made or distributed for profit or commercial advantage AND that copies 1) bear this notice in full and 2) give the full citation on the first page. It is permissible to abstract these works so long as credit is given. To copy in all other cases or to republish or to post on a server or to redistribute to lists requires specific permission and payment of a fee. Contact Publisher@InformingScience.org to request redistribution permission.
The use of ICT in school allows enhancement of teaching and learning beyond the walls of the classroom. This meets a wide range of school-related needs, such as repeat practice for students, access to materials that are not available in school, and so on (Ally, 2004; Picciano \& Seaman, 2007). Therefore, many schools around the world have been introducing online courses or blended learning. But whe-

\section{Editor: Alex Koohang}

An earlier, shorter version of this paper was presented at the Chais conference 2010, in Raanana, Israel, and included in Y. Eshet-Alkalai, A. Caspi, S. Eden, N. Geri, \& Y. Yair (Eds.), Proceedings of the Chais conference on instructional technologies research 2010: Learning in the technological era. Raanana: The Open University of Israel. http://www.openu.ac.il/research center eng/conferences.html 
reas the teacher has significant control over students' online learning process in the classroom, outside the classroom the students confront the assignments alone. They have more responsibility for their learning and are required to demonstrate autonomy and independence in learning.

The degree of students' control in online learning is reflected in the way they choose to consume the content: the path, the pace, and the duration of learning, as well as the effort they are willing to invest (Beck, 2007; Sims \& Hedberg, 1995). This will yield different patterns of learning. Previous research showed that factors like gender (McSporran \& Young, 2001) and age (Cavanaugh, Gillan, Kromey, Hess, \& Blomeyer, 2004) are correlated with certain aspects of online learning behaviors. Moreover, several studies showed a need for young students to be scaffolded as part of the distance learning experience; only by the time they are enrolled in higher education may they acquire a degree of autonomy in learning (Cavanaugh, 2005). Many schools, therefore, are concerned about their students' quality of learning and level of readiness for autonomous online learning (Picciano \& Seaman, 2007). Hence, there is a need to enhance our understanding of learning behaviors, especially how learners proceed with and without teacher presence, i.e., at school and at home.

However, when working with a large population, learners' online behaviors are not easily traced with traditional research methodologies, such as questionnaires and observations (Nachmias \& Hershkovitz, 2007). Analysis of the data documented in the log file can help us with this type of mission. While they are learning in online environments, students actually leave a continuous trace of their activity in the form of $\log$ file records, which document every action taken with reference to three parameters: what was the action taken, who took it, and when. Extracting these actions from the log files and analyzing them can yield meaningful information and new insights about how students learn in online environments and about their learning styles and needs (Pahl, 2004; Romero \& Ventura, 2007).

Our aim in this study is to analyze the data derived from students' log files in order to learn more about online learning processes at home and in school, and also to explore if there are certain behavioral differences in both locations in terms of age and gender.

\section{Background}

\section{Online Learning}

Online learning in K-12 has become more widespread in the past decade. According to a 2008 report by the U.S. Department of Education, the number of K-12 public education students who enrolled in technology-based distance education grew by 65\% between 2002-03 and 2004-05 (Zandberg \& Lewis, 2008). Picciano and Seaman (2007) estimated that more than a million K-12 students took online courses in the 2007-2008 school years.

One of the most valuable benefits of integrating ICT in school practice is that it enhances the possibilities of teaching and learning beyond the traditional limitations of time and space (Arbelaiz \& Gorospe, 2009; Tubin, Mioduser, Nachimias, \& Forkosh-Baruch, 2003). Our previous research (Ben-Zadok, Leiba, Nachmias \& Mintz, 2009) revealed that many schools in Israel exploit this advantage by using the online environment for home tasks and independent learning.

Much research has been done regarding the contribution of online and blended learning. Results point out, for example, that such learning offers contents not otherwise available at school, that it meets the needs of specific groups of students, and that it reduces scheduling conflicts (Picciano $\&$ Seaman, 2007). Students can access the online learning material any time and get up-to-date and relevant learning materials (Ally, 2004). However, when schools want to integrate online learning environments in class, they have to struggle with obstacles such as the availability and 
accessibility of computers (Pelgrum, 2001; Rogers, 2000). As a result, students experience difficulties in completing learning assignments in school. Home, therefore, may offer a useful environment for students to continue their online learning assignments. But whereas in the classroom the presence of the teacher can control and influence the learning process, at home students are left to their own devices.

Research comparing online learning to traditional learning indicates that when they use a computer students do assignments more in their own way and assume greater responsibility for their learning, working both more independently and effectively (Balanskat, Blamire, \& Kefala, 2006). Learners control their learning processes and choose their own mode of learning. For example, they may choose the content they want to engage with, the time and the pace of learning, or the learning sequence (Sims \& Hedberg, 1995). This phenomenon has led researchers to want to study online learners' behaviors and learning processes in greater depth, to reveal, among other things, factors that influence students' modes of learning.

\section{Computer Use in School and at Home}

Another reason why we want to compare learning behaviors in school vs. at home is the additional fact that children's attitudes to computers in school and at home are diverse. Several studies showed that whereas they consider using computers at home enjoyable, students found school use "tame" (Mumtaz, 2001; Underwood, Billingham, \& Underwood, 1994). Underwood et al. (1994) found that when computers are used for drill and practice, students find these activities time consuming and boring. Kent and Facer 's (2004) findings indicate that at home young people tend to engage in computer activities associated with leisure, such as games or media activities - activities that are often less usual in school. Schools, in contrast, are an important gateway for many young people to engage with resources, for instance, through mathematical manipulations, something they will less frequently do in the home environment.

The nature of use also differs between home and school. Earlier studies identified significantly higher frequencies of computer use at home than in school and also described differences in the types of activities. Some studies showed that most participants regularly used their computers at home for playing games, and that computer games, indeed, constitute children's most popular activity in the home; in school, by contrast, the computer serves as a learning and working tool (Kent \& Facer, 2004; Mumtaz, 2001; Underwood et al., 1994). Ayik (2008) found that students' computer-related activity at home and in school differed in terms of frequency and duration of use as well as of application preference: computer use is more frequent and longer at home than in school. At home, the students use the computer as they want it, for as long as required, and they behave more flexibly.

\section{Individual Differences in Computer Related Behavior}

Studies that looked at learning differences found a large variability in students' use of e-learning components in terms of, for example, participation in discussion groups, running simulations, reading information, watching presentations, and voting in polls (Leiba \& Nachmias, 2006, Nachmias \& Segev, 2003; Peled \& Rashty, 1999). It was also found that individual differences significantly affect students' online learning. Variables such as gender (McSporran \& Young, 2001; Peled \& Rashty, 1999), age (Cavanaugh et al., 2004), culture (McGee, 2002), and learning styles (Sabry \& Baldwin, 2003) seem to indicate different patterns in learning preferences, usage, and interactions in online learning environments. Our study focuses on two such variables: age and gender. 


\section{Age}

In their extensive survey of U.S. K-12 schools, Picciano and Seaman (2007) reported that many school districts have concerns about the quality of online education and student readiness for this type of learning. Even in higher education, problems with the readiness of students to participate and succeed in an online course have been well-established, but in K-12 schools, especially at the primary and middle school level, where students' social and emotional development is an important aspect of the overall school experience, student readiness is a greater concern. The authors suggested that blended instruction, by providing some face-to-face time, would be a better option where these concerns arise.

Online learning requires a wide range of basic skills, including for instance self-regulation and time management. These skills seem to be under-developed among young students (especially boys) (McSporran \& Young, 2001). Autonomy and responsibility are crucially needed for online learning, but they are acquired skills and only by the time students reach higher education will most of them have acquired a degree of autonomy in learning (Cavanaugh et al., 2004).

Readiness to learn by means of the computer is also associated with learners' experience with computers after school hours. Here research shows different types of computer use after school hours for different age groups. Age was found to be a significant factor associated with young people's type of computer activity at home. As they grow older, children, overall, tend to use computers less frequently for leisure activities but more frequently for learning tasks (Colley, 2003; Colley \& Comber, 2003). Another aspect of differences in home-based vs. school-based use of computers is children's perceptions of computer use. Levin and Barry (1997) investigated how children perceived computers, at home and in school, through interviews and children's' drawings. They found that children in Grades 3-5 drew pictures showing the computer as a tool for doing work. The younger children in kindergarten through Grade 2 perceived computers as a games machine.

Research into the relation between age and learning behaviors found relatively small differences among age groups in terms of, for example, quality of and engagement in learning (Kay \& Knaack, 2008), or time management and online communication (McSporran \& Young, 2001). However, more research on the differential impact of age on learning behaviors is needed.

\section{Gender}

Numerous studies have investigated the role of gender in computer behaviors and most of them have focused on computer attitude, ability, or use. Overall, one could say there is a persistent pattern of small differences in computer attitude, ability, and use that often favor males (Kay \& Knaack, 2008).

Research on gender differences in students' computer use outside school found that in the elementary years boys tend to use computers more frequently than girls (Hakkarainen et al., 2000; Nelson \& Cooper, 1997). Boys are also more likely to play computer games than girls (Hakkarainen et al., 2000; ). Vekiri and Chronaki (2008) also found that, although almost all students used computers outside school, there were significant gender differences in frequency and type of use. Boys tended to use computers on a regular basis and were more likely to use computers in public places such as internet cafes or to talk about and to use computers when they met with their friends. Boys had more positive self-efficacy and value beliefs about computers compared to girls. For the girls the computer did not serve as a main tool in their everyday activities. Although girls were equally likely to have a computer at home or in their own room, they used computers less often than boys. 
Research revealed some gender differences in various aspects of online learning. For example, Leiba and Nachmias (2006) explored gender differences in content consumption in an online environment and found that girls tend to consume more online content materials than boys and read more messages in discussion groups. McSporran and Young (2001) found that girls in an online course were more motivated and better at communicating and at scheduling their learning. Other studies revealed behaviors that were similar for boys and girls. For example, Kay and Knaack (2008) found no gender differences with respect to four aspects: student perception of learning, quality, engagement, and performance.

\section{Log File Analysis for Understanding Learning Behaviors}

It is not easy to study the online learning behaviors of a large student population with traditional research methods such as questionnaires or observations (Nachmias \& Hershkovitz, 2007). While questionnaires are based on self reports and observations are practically impossible with large number of subjects, analysis of log files offers the opportunity to learn about the behaviors of students in a large population and collect actual behaviors in a non intrusive way.

While students engage in online learning they leave continuous traces of their activity in the form of $\log$ file records, which document every action taken by reference to three parameters: what was the action taken (e.g., the page URL, the file downloaded); who took it (if the system requires login, this field will usually include student identification), and when (exact time). Researchers analyze this data to identify different aspects of learning behaviors, such as patterns of navigation, time spans, and sequences of learning (Romero \& Ventura, 2007). The log files of online learning environments might also hold information about students' profile (e.g., age, gender, achievements), so it becomes possible to correlate between their behaviors and their personal profile.

Studies exploring online learners' behaviors through their actual behaviors as reflected in log files deal with both cognitive and affective aspects of learning, using a choice of measurable variables. Beck (2004), for example, examined engagement in learning by using two learning variables: question response time and answer correctness. Cocea and Weibelzahl (2007) examined engagement in learning by means of the variables number of pages read, time spent reading pages, number of tests/quizzes, and time spent on test/quizzes. Hershkovitz and Nachmias (2008) examined motivation for learning by referring to variables such as: time on task, pace of activity per session, and average time between sessions.

Some studies focus on the relationship between online learners' behaviors and their achievements. Morris, Finnegan and $\mathrm{Wu}$ (2005), for example, found that unsuccessful students were far less active in terms of course participation than successful students. Hwang and Wang (2004) found correlation between the times during which the learner was active and his or her achievements, and Rafaeli and Ravid (1997) examined the correlations between usage behavior measures in the online environment and student achievement and found that achievement was positively correlated with actual amount of reading, and also that online usage behavior variables predicted $20 \%$ of the variance in a student's grade.

In this study we analyzed data derived from students' log file in an online science learning environment, in order to learn about differences in learners' behaviors - in school vs. at home, across ages and genders. 


\section{Research Questions}

The study poses three main questions:

1. Are there any differences in online learning behaviors in school vs. at home, in terms of: time on task, pace of learning, amount of completed activities, sequence of learning, use of simulation, and achievements?

2. Are there any gender differences in these learning behaviors in school vs. at home?

3. Are there any age differences in these learning behaviors in school vs. at home?

\section{Method}

Students' actions in a specific science module were documented in a log file and statistically analyzed in order to learn about their learning behaviors in school and at home and to compare between them.

\section{Participants}

Participants were 1,179 third to sixth grade students (8-12 year-old children) from elementary schools in Israel, who were learning in the module either in school or at home, usually as homework.

The age groups included: 567 students in third grade - 276 learned in school, 291 at home; 279 students in fourth grade - 143 learned in school, 136 at home; 245 students in fifth grade - 166 learned in school, 79 at home; 88 students in sixth grade - 39 learned in school, 49 at home.

In the gender comparison 881 students were examined: 404 boys - 197 learned in school, 207 learned at home; 477 girls - 252 students learned in school, 225 students learned at home.

\section{The Learning Environment}

The researched learning module is a part of Ofek (http://ofek.cet.ac.il) - an online learning environment, to which over 1,000 elementary schools all over Israel subscribe. Students can learn in this environment either in school (in the classroom or in the computer lab), as a part of a lesson with their teacher, or at home (in the teacher's absence). Either way assignments in the module are given by the teacher, through a LMS (Learning Management System).

The learning module we chose to work with deals with earth science: the concept of the month and the phenomenon of lunar phases. It offers a linear presentation through six types of activities, in the following order:

Activity 1: Simulation. The simulation visualizes the orbit of the moon around the earth and the phases of the moon during the month. Students can run the simulation either continuously or in stages, and make their observations. The simulation also includes audio and textual explanations.

Activities 2-4: Drill and practice exercises. Each exercise includes 4-5 questions which relate to the information presented in the simulation. The exercises include immediate feedback to the students.

Activity 5: Game. The goal of the game is to complete the moon's monthly phases. The game has three levels and feedback in terms of wins or losses at the end.

Activity 6: Self-test. The test includes 10 summary questions on different cognitive levels. It also contains auto-checking and grading. The students get 10 scores for each correct answer and can fix their answers until they reach a score of 100. 


\section{Procedure}

Data drawn from a large population that interacted with the module were collected and documented in the log file over a period of four months (September 2009 - December 2009). Each action (mouse click) by a user was documented with its exact time and the exact nature of the action (for example, answering a question, dragging a component, or pushing the check button). Data processing and analysis were carried out in four consecutive phases:

Phase I - Data exploration - this phase focuses on collecting, describing, and exploring the data. During this phase we examined the dataset and the format of the basic variables.

Phase II - Data preprocessing - this phase focuses on cleaning and formatting the data. The original dataset consisted of $\mathrm{N}=1,491$ cases initially.

The cleaning of the dataset included:

(a) Deleting the user data of non-students (administrators and teachers), since online learning was the focus of the study.

(b) Keeping only third to sixth-graders, since the study centered on students who were learning the module as part of their curriculum.

(c) Excluding students who learned in the module both in school and at home.

(d) Excluding students who either spent less than one minute in the module (because this indicates that they did not learn with it) or spent more than 90 minutes in the module: This was because we were aware of the fact that students who learn at home may leave the module open on the screen for much beyond their actual learning time.

The new set of processable data obtained after this cleaning was $\mathrm{N}=1,179$.

Phase III - Computing variables - previous research, which inquired into the same science module, found several variables that reflect the variability in students' behaviors: Time on Task, Pace of Learning, Completed Activities, Linearity, and Simulation Use (Ben-Zadok, Hershkovitz, Mintz \& Nachmias, 2009). These variables were adopted for the current research framework. Algorithms for calculating the variables were formulated and implemented using EXCEL. The study variables are shown in Table 1.

Phase IV - Employing descriptive statistics - Independent $t$-tests and Anova were performed using SPSS for comparing between groups. The comparison between age groups and genders was carried out only for students for whom we actually had this information (age: $\mathrm{N}=1,179$, gender: $\mathrm{N}=881$ ) in the log file. The comparison concerning the test scores was carried out only for students who did the test $(\mathrm{N}=701)$.

\section{Variables}

Below we describe the variables which we extracted and computed from the log file:

\section{Location of learning}

The location of learning was determined by the time of learning. Since we recorded the exact time of the student's first and last action (mouse click) in the module we could calculate his or her learning time and determine if it occurred during school hours or after. We determined the location as school if the learning occurred between 8:00 am and 14:00 pm, and we determined the location as home if the learning occurred between 14:00 pm and 8:00 am. 


\section{Time on task}

This variable was measured as the total time between a student's first action (mouse click) and final action within one session in the learning module. The values of this variable range between $0-5,400$ seconds. This variable was commonly measured in various studies (e.g., Jonker \& Wijers, 2008; Steinke, Huk, \& Floto, 2004) as the time spent by a student in the learning task. Time on task takes into account the actual time spent actively working on an activity but also time dedicated to other activities (e.g., thinking, reflecting, surfing the web, etc.). The latter may compromise the validity of the measured variable.

\section{Pace of learning}

The pace of learning was calculated as the number of a student's actions (mouse clicks) in the learning module divided by Time on Task (clicks/sec).

\section{Completed activities}

As mentioned, the learning module includes six activities. For each student we calculated how many activities (out of six) he or she completed before leaving the module. We did not include cases in which the student completed an activity more than once.

\section{Linearity}

The learning module presents the study content consecutively, i.e., each one of the six activities follows the next. Our goal was to examine the sequence of students' learning: whether or not they completed the activities in the same order as they appeared in the module. To achieve this we examined the steps from one activity to another. Linear steps were determined when the next step consisted of a forward movement to the next activity in the sequence. In this case we marked this step FW1. Any other movement, backward or forward, was considered nonlinear. We also took the student's first step into account. For example, if she or he skipped the simulation and went directly to the drill and practice exercise, this step was calculated as two steps forward (FW2). The value of the Linearity variable was calculated as the percentage of a student's linear steps out of all her or his steps in the module.

\section{Simulation use}

This variable expresses the number of times a student visited the simulation during learning. In general, a student could visit the simulation just once, at the beginning of the learning, or more, when performing other activities, for collecting information. A student could also avoid the simulation. We did not consider the time spent in the simulation for each visit.

\section{Test score}

The test includes automatic feedback and grading. When (and only when) a student finishes answering all questions he or she gets his scores. The student then can fix her or his answers as many times as he or she wants until full grade (100 score) is achieved. But for measuring each participant's achievements in the module, we took into account only their first score in the test. The values of this variable ranged between 0-100.

\section{Ethical Issues}

Log file analysis enables us to trace the students' activities on the web without her or him being aware of this being the case. This encapsulates several ethical concerns. First, private data may become public. Second, these data can be used for in-appropriate purposes. All log traces used in this research were collected by the LMS with the full consent of Israel's Educational Board, for 
the purpose of local learning evaluation by individual teachers. The data for this research was made available in anonymous form, with all personal details (e.g., student's name, school, and city) deleted. This made it impossible to identify the students and to compromise their privacy.

\section{Results}

\section{Students' Online Behaviors in School vs. at Home}

A summary of the students' behaviors and achievements in school vs. at home with reference to all six variables is presented in Table 1.

Table 1: Comparison between learning behaviors in school vs. at home

\begin{tabular}{|l|l|l|l|l|}
\hline \multirow{2}{*}{ Variable } & \multicolumn{2}{|l|}{ Location of Learning } & \multirow{2}{*}{ t } & \multirow{2}{*}{ N } \\
\cline { 2 - 4 } & School $M(S D)$ & Home $M(S D)$ & & \\
\hline Time on Task (seconds) & $564.35(504.14)$ & $830.42(800.35)$ & $-6.90^{* *}$ & \\
\cline { 1 - 4 } Pace of Learning (seconds/actions) & $.15(0.92)$ & $.12(0.73)$ & $6.59^{* *}$ & \\
\cline { 1 - 4 } Completed Activities & $4.22(2.03)$ & $4.26(2.10)$ & -0.33 & \multirow{2}{*}{1,179} \\
\cline { 1 - 4 } Linearity (\%) & $79.90(25.34)$ & $80.47(25.19)$ & -0.42 & \\
\cline { 1 - 4 } Simulation Use & $1.41(1.25)$ & $1.51(1.24)$ & -1.38 & \\
\hline Test Score & $60.97(20.85)$ & $65.19(19.67)$ & $-2.75^{* *}$ & \multirow{2}{*}{701} \\
\hline
\end{tabular}

$* * p<0.01$

A comparison between Time on Task in school and at home indicates that at home students tend to learn in the module 830.42 seconds on average $(S D=800.35)$ compared to an average of 564.35 seconds in school $(S D=504.14)$; i.e., students spend $32 \%$ more time on task at home $(t=$ $-6.90, p<0.01$ ). The distribution of students' Time on Task (Figure 1) shows that a majority of students, both in school and at home, spent between zero to 1,000 seconds (approximately 0-17 minutes) in the module. The data also reveal that more students spent between 2,000 to 4,000 seconds (approximately 0.5-1 hour) on task at home than did in school.

Examination of students' Pace of Learning indicates that students tend to learn at a slower pace at home (at a rate of 0.12 actions/second $[S D=0.73])$ than at school $(0.15$ seconds/actions $[S D=$ $0.92 t=6.59, p<0.01])$.

No significant difference was found in the average of completed activities in school vs. at home (average in school $=4.22, S D=2.03$; average at home $=4.26, S D=2.10 ; t=-0.33, p>0.05$ ). The distributions of the completed activities at home and in school are similar. We also found that similar percentages of students (almost half of them), both at home and in school, completed all six activities that make up the module.

The average percentages of Linearity in school and at home are similar (average in school $=$ 79.90, $S D=25.34$; average at home $=80.47, S D=25.19 ; t=-0.42, p>0.05$ ). It seems that students tend to consume the content in its order of appearance in the module and don't move back and forth between activities at random. The percentage distribution of Linearity indicates that more than $60 \%$ of the students consume the content in $80 \%$ linear mode, and $40 \%-45 \%$ of them consume the content in full linear mode $(100 \%)$. 


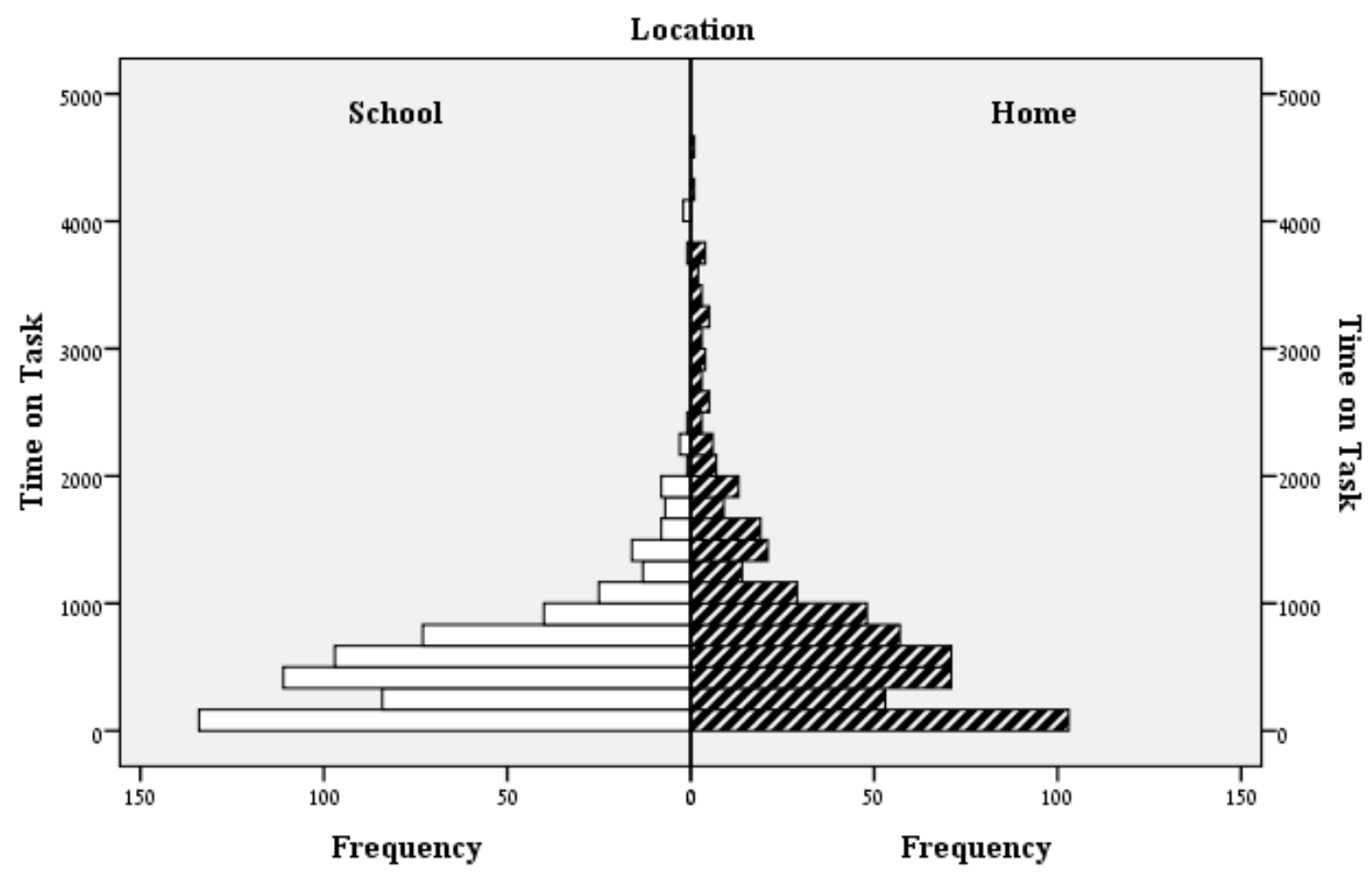

Figure 1: Distribution of students' Time on Task in school vs. at home $(\mathrm{N}=1,179)$

Results suggest no significant difference in the amount of visits in the simulation during learning at home vs. school. In both settings students visited the simulation once or twice (average in school $=1.41, S D=1.25$; average at home $=1.51, S D=1.24 ; t=-1.38, p>0.05)$. However, arranging the number of visits on a scale ranging between 0 and $2+$ (with $0=$ student never visited the simulation; $1=$ student visited simulation just once; $2+=$ student visited simulation twice or more during the learning process) showed that in school the percentage of students who visited the simulation just once is larger, while at home the percentage of students who visited the simulation twice or more is larger. The percentage of students who did not visit the simulation at home is quite similar to that in school.

Comparisons between student scores in the self-test shows that students tend to score higher at home than in school. The average score at home is $65.19(S D=19.67)$ as opposed to $60.97(S D=$ $20.85)$ in school $(t=-2.75, p<0.01)$. The distribution of scores indicates that the percentages of students who scored 100 were similar in school and at home, but the percentage of students who scored between 70-90 is higher at home than in school.

\section{Learning Behaviors in School and at Home in Different Age Groups}

Comparison of the variables in school and at home across ages reveals significant differences in Time on Task and Pace of Learning for all ages (Figures 2-3). This means that all students from third grade to sixth grade tend to learn over more time and at a slower pace at home than in school. In all other variables, Completed Activities, Linearity, Simulation Use and Test Score, we found no significant differences between school and home in each age group.

Comparison between age groups, by the averages of the variables in both school and home, reveals differences in three behaviors: Time on Task, Pace of Learning and number of Completed Activities (Figures 2-4). Anova tests indicate that students in third grade behave differently from older students in the time variables; they learn for longer stretches in the module and do so more 
slowly $(\mathrm{F}(3,1178)=15.30, p<0.01)$. Tukey contrast test reveals that the average of the completed activities in third and fourth grades differs significantly from that in fifth and sixth grades $(\mathrm{F}(3,1178)=14.37, p<0.01)$. This suggests that older students tend to complete more activities than younger students.

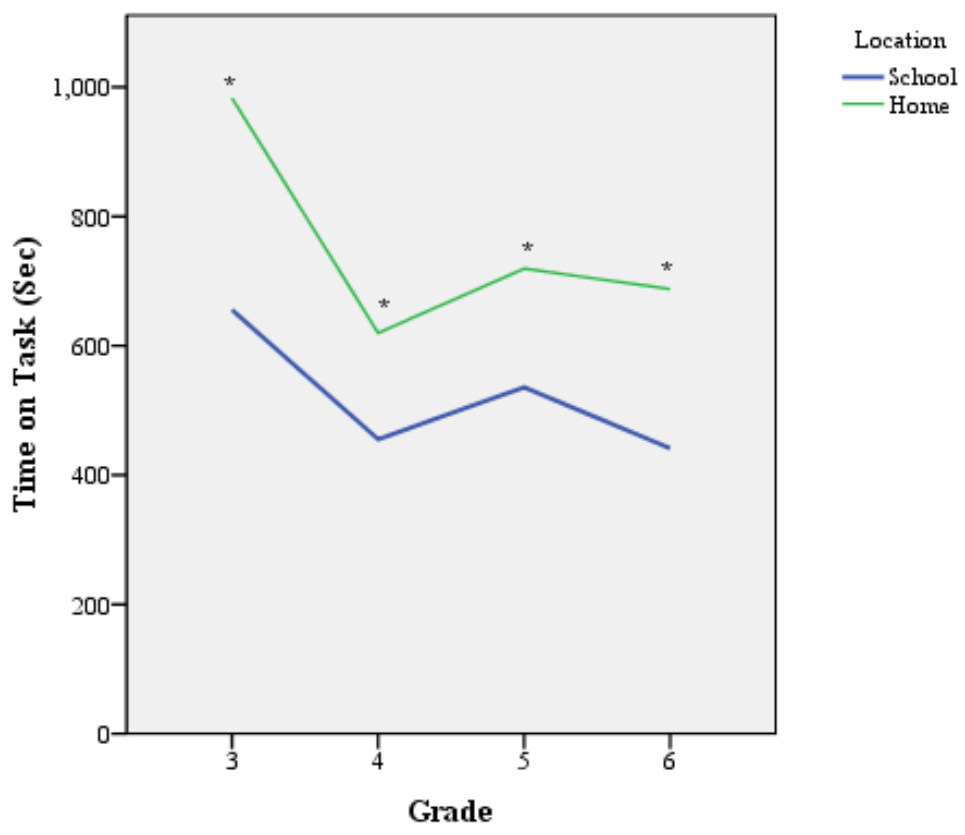

Figure 2: Comparison of Time on Task in school vs. at home across ages (The asterisks indicate significant differences)

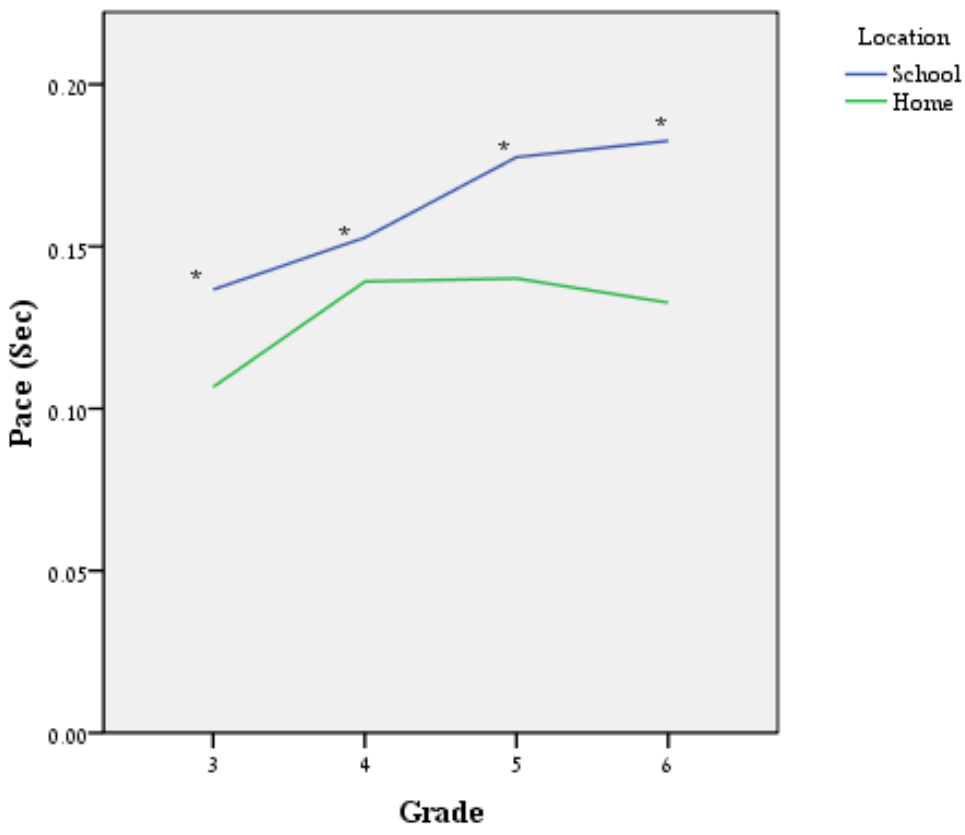

Figure 3: Comparison of Pace of Learning in school vs. at home across ages (The asterisks indicate significant differences) 


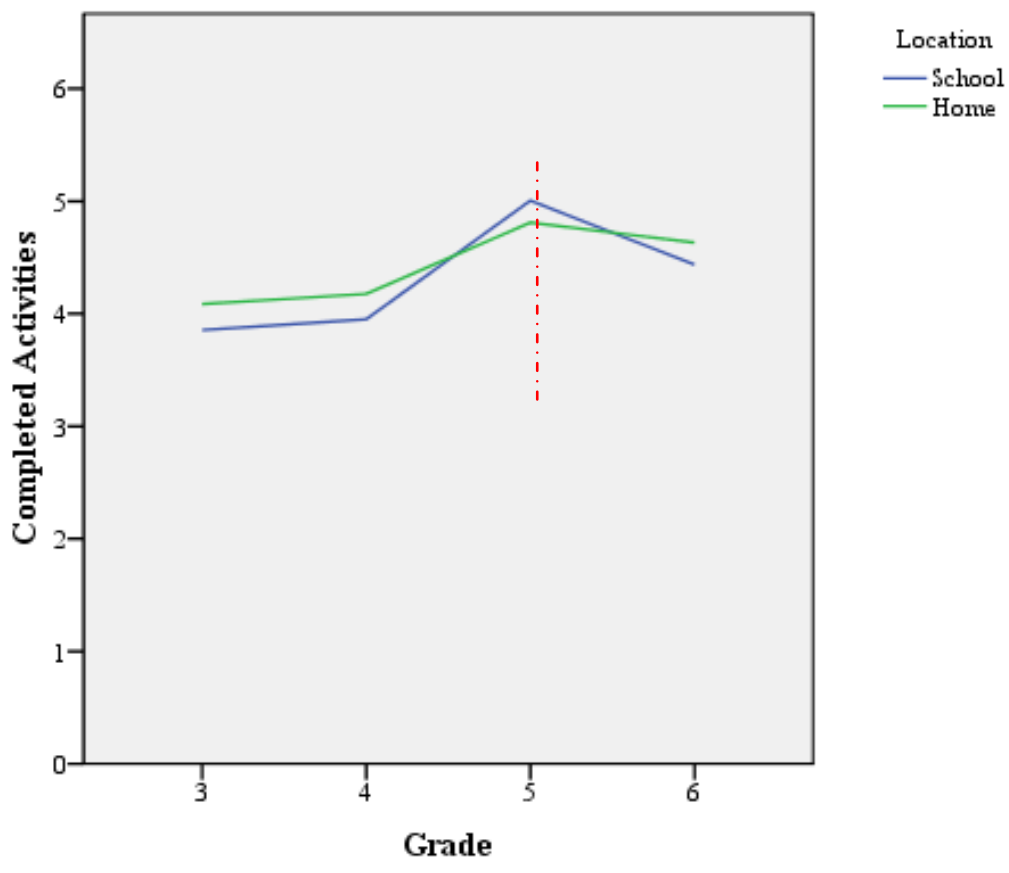

Figure 4: Comparison of Completed Activities in school vs. at home across ages (The dotted line separates between the two age groups)

No significant differences among ages were found in the other variables. This suggests that, in general (in school and at home), students from third grade to sixth grade have similar learning behaviors: they learn pretty much in linear fashion (approximately 80\%), they use the simulation during their learning once or twice, and they score around 60 points.

\section{Learning Behaviors in School and at Home in terms of Gender}

The values of all variables in school and at home for boys and girls are presented in Table 2. In both groups significant differences were found between school and home in the time variables: Time on Task and Pace of Learning. Both gender groups tend to learn for more time at home and at a slower pace. A look at the Completed Activities variable indicates a slight difference in the boys group in favor of home (average in school $=4.13$ actions/second; $S D=2.06$; average at home $=4.66$ seconds/actions; $S D=1.91 ; t=-2.64 ; p<0.01$ ).

Comparison in terms of gender by variable averages in school and at home (Table 3 ) indicates slightly significant differences in two variables: Pace of Learning and Test Score. Girls learned faster in the module than boys (girls' average pace $=0.14$ seconds/actions; $S D=0.08$, boys' average pace $=0.12$ seconds/actions; $S D=0.07 ; \mathrm{p}<0.05)$ and achieved higher scores on the test (girls' average score $=66.50 ; S D=20.00$, boys' average score $=62.85 ; S D=19.95 ; p<0.05$ ). All other behaviors are similar: boys and girls spent similar time on the task (about 11 minutes), they completed similar average amount of activities (approximately 4 activities out of 6), they learnt linearly $(80 \%)$, and they used the simulation once or twice in their learning. 
Table 2: Comparison between learning behaviors in school vs. at home in terms of gender

\begin{tabular}{|c|c|c|c|}
\hline \multirow{2}{*}{ Variable } & \multicolumn{2}{|c|}{ Location of Learning } & \multirow{2}{*}{$t$} \\
\hline & School $M(S D)$ & Home $M(S D)$ & \\
\hline \multicolumn{4}{|c|}{ Time on Task (seconds) } \\
\hline Boys & $603.17(478.07)$ & $832.34(710.20)$ & $-3.78 * *$ \\
\hline Girls & $507.40(432.46)$ & $806.20(828.47)$ & $-5.01 * *$ \\
\hline \multicolumn{4}{|c|}{ Pace of Learning (seconds/actions) } \\
\hline Boys & $0.13(0.08)$ & $0.11(0.06)$ & $2.78^{* *}$ \\
\hline Girls & $0.15(0.08)$ & $0.12(0.07)$ & $3.58^{* *}$ \\
\hline \multicolumn{4}{|c|}{ Completed Activities } \\
\hline Boys & $4.13(2.06)$ & $4.66(1.91)$ & $-2.64 * *$ \\
\hline Girls & $4.08(2.06)$ & $4.26(2.11)$ & -0.97 \\
\hline \multicolumn{4}{|c|}{ Linearity (\%) } \\
\hline Boys & $80.85(25.04)$ & $81.12(21.11)$ & -0.11 \\
\hline Girls & $79.83(25.18)$ & $80.60(21.05)$ & -0.36 \\
\hline \multicolumn{4}{|c|}{ Simulation Use } \\
\hline Boys & $1.32(1.18)$ & $1.51(1.21)$ & -1.57 \\
\hline Girls & $1.41(1.23)$ & $1.54(1.38)$ & -1.08 \\
\hline \multicolumn{4}{|c|}{ Test Score } \\
\hline Boys & $61.37(20.77)$ & $63.92(19.33)$ & -0.98 \\
\hline Girls & $65.35(20.79)$ & $67.60(19.23)$ & -0.94 \\
\hline
\end{tabular}

Table 3: Comparison between boys and girls by the average variables in school and at home

\begin{tabular}{|llll|}
\hline Variable & Gender & & \\
& Boys & Girls & $t$ \\
Time on Task (seconds) & $M(S D)$ & $M(S D)$ & \\
Pace of Learning (seconds/actions) & $0.12(0.07)$ & $0.14(0.08)$ & $-2.51^{*}$ \\
Completed Activities & $4.40(2.00)$ & $4.16(2.09)$ & -1.71 \\
Linearity (\%) & $80.99(23.08)$ & $80.19(23.30)$ & 0.50 \\
Simulation Use & $1.42(1.20)$ & $1.47(1.30)$ & -0.62 \\
Test Score & $62.85(19.95)$ & $66.50(20.00)$ & $-2.09 *$ \\
\hline$* p<0.05$ & & & \\
\hline
\end{tabular}




\section{Discussion}

We formulated two research objectives: to compare online learning behaviors of elementary school students in school vs. at home, and also to explore if there are some behavioral differences, in school and at home, in terms of age and gender. The log file analysis enabled us to study not only the learning outcomes but the learning processes as well, in a non-intrusive and objective way. Integration of the documented trace data of the online learners with their personal profiles stored in the system of the learning environment allowed us to enhance our understanding of the nature of the relations between age/gender and learning processes in school vs. at home.

Examination of students' learning behaviors in school vs. at home indicates that learning at home does not essentially differ from in school. It seems that at home, as in school, students set aside time for learning and devote attention to the assignments, also without the teacher's supervision. This finding is interesting because other studies have shown that students tend to deem computer use for learning boring and a "waste of time" (Mumtaz, 2001; Underwood et al., 1994). This finding may also refute a concern many schools have regarding the quality of learning and the level of student readiness for autonomous online learning (Picciano \& Seaman, 2007). In addition, results show similar learning behaviors at home and in school in terms of the rate of simulation use, the amount of completed activities, and the nature of the learning sequence. In both locations most students tended to use the simulation during the learning process, to complete a major part of the activities, and to learn in linear fashion. Therefore, we may suggest that these learning behaviors relate to personal characteristics rather than the location of learning. However, we found important differences in connection with the time-related variables, Time on Task and Pace of Learning, and also with the Test Score variable. It seems that at home students tend to spend more time in the module (32\% more) and to learn at a slower pace, and these students score higher in the test. This may be because students who learn at home were not restricted by time; were more relaxed, and not distracted by their peers, and therefore could focus better on the task. Another interpretation could be related to the time students actually need to learn; in school they are constrained by the duration of the lesson. Our results are in line with other studies that describe the advantages of online learning environments where learners have control over the time, pace, and duration of learning (Balanskat et. al 2006; Harasim, 1996). It is worthwhile mentioning that Time on task takes into account both the actual time spent working on an activity and time dedicated to other activities (e.g., thinking, reflecting, surfing the web, and out of the environment.). This may compromise the validity of the measured variable, a limitation that has to be considered carefully.

Comparison of the learning behaviors in school vs. at home within each age group and gender group revealed results similar to those of the whole researched group of students (except that boys tended to perform more activities at home than in school, but this difference was very slight). This implies that age and gender are not related to the differences found between school and home behaviors. Future research in this area may look for other individual variables relevant to these differences.

Comparison between age groups with regard to online learning behaviors reveals that in general young students do not differ from older ones in the way they learn. But they do differ in timerelated variables: our younger participants learned at a slower pace, spent more time on the assignment, and performed fewer activities within a specific duration. This finding may have implications regarding young students' readiness for autonomous learning (Cavanaugh et al., 2004) in which they manage their own learning time. An explanation for this finding may relate to the content of the researched module which is difficult for young students to engage with (Hans, Kali, \& Yair, 2007). In order to examine whether the results relate to the content or the level of the studied assignment and its suitability to different ages, more research is required. 
Gender did not seem to influence the learning behaviors. Boys and girls showed generally similar behaviors in school and at home. These results are in line with Kay and Knaack's (2008) findings, according to which there were no gender differences in terms of quality, engagement, or performance in learning. Perhaps the differences are more prominent when examining aspects like sharing and communication online, as other studies indeed have shown (Leiba \& Nachmias, 2006; McSporran \& Young, 2001). Moreover, although research reveals that males use computers more often (Hakkarainen et al., 2000; Nelson \& Cooper, 1997; Vekiri \& Chronaki, 2008), it makes clear, as our study also bears out, that this does not necessarily promise different learning behaviors.

Many studies describe the added value of online environments for teaching and learning (Linn, Lee, Tinker, Husic \& Chiu, 2006; Mintz \& Nachmias, 1998; Osborne \& Hennessy, 2003), but other studies mention the difficulties teachers experience when they have to cope with ICT use in school (Pelgrum, 2001; Rogers, 2000). In this context, our main conclusions from this study are that extending teaching and learning time and boundaries to include the home using online learning environments is possible and worthwhile, regardless of age or gender. We think that one of the challenges today is to transfer part of teaching and learning from school to home. By doing this, teachers can exploit the advantages of online environments for their teaching goals, extend teaching time, and also enable students to learn and practice the learning materials in their own time and at their own pace. The main concern is regarding the teacher's role in the online learning. Since we found that learning behaviors in school and at home are quite similar, it may be assumed that the effectiveness of teachers' intervention in the learning process in class is limited. Future research, therefore, will have to address the teacher's role in the learning process as well as the appropriate pedagogical model for optimal integration of the online environment in class.

\section{References}

Ally, M. (2004). Foundations of educational theory for online learning. In T. A. Anderson \& F. Elloumi (Eds), Theory and practice of online learning (pp. 3-31). Athabasca University.

Arbelaiz, M., \& Gorospe, C. (2009). Can the grammar of schooling be changed? Computers \& Education, 53(1), 51-56.

Ayik, Y. Z. (2008). The computer perception of students at home, at school and at Internet Cafe and the comparison of the computer applications they preferred: A survey in Erzurum, Turkey. IADIS International Conference on Interfaces and Human Computer Interaction (pp. 297-301).

Balanskat, A., Blamire, R., \& Kefala, S. (2006). The ICT impact report. A review of studies of ICT impact on schools in Europe. Brussels: European Schoolnet (http://insight.eun.org).

Beck, J. E. (2004). Using response times to model student disengagement. Proceedings of the Workshop on Social and Emotional Intelligence in Learning Environments, 7th International Conference on Intelligent Tutoring Systems, Maceio, Brazil.

Beck, J. E. (2007). Does learner control affect learning? Proceedings of the 13th International Conference on Artificial Intelligence in Education (AIED 07) Los Angeles (pp. 135-142).

Ben-Zadok, G., Leiba, M., Nachmias, R., \& Mintz, R. (2009) Anywhere, anytime? Examining students' online learning behaviors at home vs. in school using data mining techniques. Unpublished manuscript.

Ben-Zadok, G., Hershkovitz, A., Mintz, E., \& Nachmias, R. (2009). Examining online learning processes based on log files analysis: A case study. 5th International Conference on Multimedia and ICT in Education (m-ICTE'09), Lisbon, Portugal.

Cavanaugh, C. (2005). Virtual schooling: Effectiveness for students and implications for teachers. In C. Crawford et al. (Eds.), Proceedings of the Society for Information Technology and Teacher Education International Conference (pp.301-308). Chesapeake, VA: AACE. 
Cavanaugh, C., Gillan, K. J., Kromey, J., Hess, M., \& Blomeyer, R. (2004). The effects of distance education on K-12 student outcomes: A meta-analysis. Naperville, IL: Learning Point Associates.

Cocea, M., \& Weibelzahl, S. (2007). Cross-system validation of engagement prediction from log files. In E. Duval, R. Klamma, \& M. Wolpers (Eds.), Creating new learning experiences on a global scale: Proceedings of the Second European Conference on Technology Enhanced Learning, EC-TEL 2007, Crete, Greece, September 17-20, 2007.

Colley, A. (2003). Gender differences in adolescents' perceptions of the best and worst aspects of computing at school. Computers in Human Behaviour, 19, 673-682.

Colley, A., \& Comber, C. (2003). Age and gender differences in computer use and attitudes among secondary school students: What has changed? Educational Research, 45(2), 155-165.

Hakkarainen, K., Ilo“maki, L., Lipponen, L., Muukkonen, H., Rahikainen, M., Tuominen, T., et al. (2000). Students' skills and practices of using ICT: Results of a national assessment in Finland. Computers and Education, 34(2), 103-117.

Hans, M., Kali, Y., \& Yair, Y. (2007). Spatial perception of the moon phases: Using design-principles for the development of a Web-based module for middle-school students. The $2^{\text {nd }}$ Chais Conference for the Study of Educational Technologies, 2007. Raanana: The Open University, Israel.

Harasim, L. (1996). Online education. In T. M. Harrison, \& T. Stephen (Eds.), Computer networking and scholarly communication in the twenty-first-century university (pp. 203-214). Albany: State University of New York Press.

Hershkovitz, A., \& Nachmias, R. (2008). Developing a log-based motivation measuring tool. Proceedings of First International Conference on Educational Data Mining. Montreal, Canada.

Hwang, W.-Y., \& Wang, C.-Y. (2004). A study of learning time patterns in asynchronous learning environments. Journal of Computer Assisted Learning, 20(4), 292-304.

Jonker, V., \& Wijers, M. (2008). Thinklets for mathematics education. Re-using computer games characteristics in educational software. Proceedings of the 8th International Conference for the Learning Sciences, pp. 406-413, Utrecht, The Netherlands.

Kay, R. H., \& Knaack, L. (2008). A formative analysis of individual differences in the effectiveness of learning objects in secondary school. Computers \& Education, 51, 1304-1320.

Kent, N., \& Facer, K. (2004). Different worlds? A comparison of young people's home and school ICT use. Journal of Computer Assisted Learning, 20(6), 440-455.

Leiba, M., \& Nachmias, R. (2006). Web usage patterns and learning styles in an academic course in engineering. In K. Fernstrom \& K. Tsolakidis (Eds.), The International Conference on Information Communication Technologies in Education (ICICTE 2006), Rhodes, Greece.

Levin, B. B., \& Barry, M. S. (1997). Children's views of technology: The role of age, gender, and school setting. Journal of Computing in Childhood Education, 8(4), 267-290.

Linn, M. C., Lee, H.-S., Tinker, R., Husic, F., \& Chiu, J. L. (2006). Teaching and assessing knowledge integration in science. Science, 313, 1049-1050.

McGee, P. (2002). Web-based learning design: Planning for diversity. USDLA Journal, 16(1).

McSporran, M., \& Young, S (2001). Does gender matter in online learning? Association for Learning Technology Journal, 9(2), 3-15.

Mintz, R., \& Nachmias, R. (1998). Teaching science and technology in the information age. Computers in Education, 45-46, 25-31.

Morris, L., Finnegan, C., \& Wu, S. (2005). Tracking student behavior, persistence, and achievement in online courses. Internet and Higher Education, 8, 221-231.

Mumtaz, S. (2001). Children's enjoyment and perception of computer use in the home and the school. Computers \& Education, 36, 347-362. 
Nachmias, R., \& Hershkovitz, A. (2007). Using Web mining for understanding the behavior of the online learner. The International Workshop on Applying Data Mining in e-Learning (ADML'07), Crete, Greece.

Nachmias, R., \& Segev, L. (2003). Students' use of content in Web-supported academic courses. The Internet and Higher Education, 6(2), 145-157.

Nelson, L. J., \& Cooper, J. (1997). Gender differences in children's reactions to success and failure with computers. Computers in Human Behavior, 13(2), 247-267.

Osborne, J., \& Hennessy, S. (2003) Literature review in science education and the role of ICT: Promise, problems and future directions. A Report for NESTA Futurelab (No. 6). Bristol: NESTA Futurelab.

Pahl, C. (2004). Data mining technology for the evaluation of learning content interaction. International Journal of E-Learning, 3, 47-55.

Peled, A., \& Rashty, D. (1999). Logging for success: Advancing the use of WWW logs to improve computer mediated distance learning. Journal of Educational Computing Research, 21(3).

Pelgrum, W. J. (2001). Obstacles to the integration of ICT in education: Results from a worldwide educational assessment. Computers and Education, 37(2), 163-178.

Picciano, A. G., \& Seaman, J (2007). K-12 online learning: A survey of U.S. school district administrators. Boston: Sloan Consortium. Available at www.sloan-c.org-publications-survey-pdf-K12 Online learning.pdf

Rafaeli, S., \& Ravid, G. (1997). Online, Web-based learning environment for an information systems course: Access logs, linearity and performance. Information Systems Education Conference, Orlando, FL.

Rogers, P. L. (2000). Barriers to adopting emerging technologies in education. Journal of Educational Computing Research, 22(4), 455-472.

Romero, C., \& Ventura, S. (2007). Education data mining: A survey from 1995 to 2005. Expert System with Applications, 33(1), 135-146.

Sabry, K., \& Baldwin, L. (2003). Web-based learning interaction and learning styles. British Journal of Educational Technology, 34(4), 443-454.

Sims, R., \& Hedberg, J. (1995). Dimensions of learner control: A reappraisal for interactive multimedia instruction. In J. L (Ed.) First International Workshop on Intelligence and Multimodality in Multimedia Interfaces: Research and Applications, University of Edinburgh, Scotland.

Steinke, M., Huk, T., \& Floto, C. (2004). The influence of cognitive abilities and the presence of 3D models on the use of task relevant content in hypermedia learning systems. In L. Cantoni \& C. McLoughlin (Eds.), Proceedings of World Conference on Educational Multimedia, Hypermedia and Telecommunications 2004, pp. 1937-1942. Chesapeake, VA: AACE.

Tubin, D., Mioduser, D., Nachimias, R., \& Forkosh-Baruch, A. (2003). Domains and levels of pedagogical innovation in schools using ICT: Ten innovative schools in Israel. Education and Information Technologies, 8(2), 127-145.

Underwood, J., Billingham, M., \& Underwood, G. (1994), Predicting computer literacy: How do the technological experiences of schoolchildren predict their computer-based problem-solving skills? Journal of Information Technology for Teacher Education, 3, 115-126.

Vekiri, I. \& Chronaki, A. (2008). Gender issues in technology use: Perceived social support, computer selfefficacy and value beliefs, and computer use beyond school. Computers \& Education, 51(3), 13921404.

Zandberg, I., \& Lewis, L. (2008). Technology-based distance education courses for public elementary and secondary school students: 2002-03 and 2004-05. (NCES 2008-08). Washington, D.C.: National Center for Education Statistics, Institute of Education Sciences, U.S. Department of Education. 


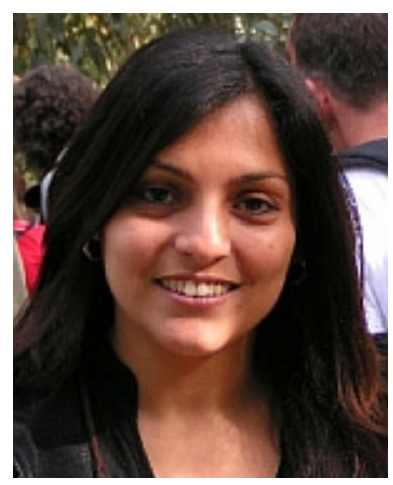

\section{Biographies}

Galit Ben-Zadok is a Ph.D candidate at the School of Education, Tel Aviv University, an educational Learning Objects' developer in the science department at CET (the Center of Educational technology) and a lecturer at Or Yehuda Center for Academic Studies. Galit's research interests are ICT in Science Education, ICT implementation in Elementary School and Web-Mining of On-line Learning.

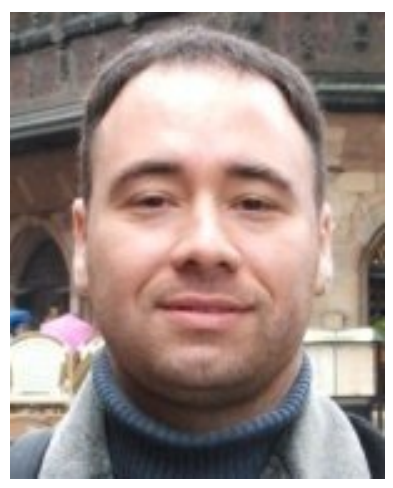

Moshe Leiba is a Ph.D candidate at the School of Education, Tel Aviv University and a lecturer at Levinsky's Teachers College. He acts as the EU research coordinator for the knowledge Technology Lab at Tel Aviv University and a research assistant at the DynaLearn project (supported by the EU $7^{\text {th }}$ Framework Programme). Moshe's research interests are ICT in Science Education, Mathematical problem solving, Web-Mining of On-line Learning and ICT in teachers' training.

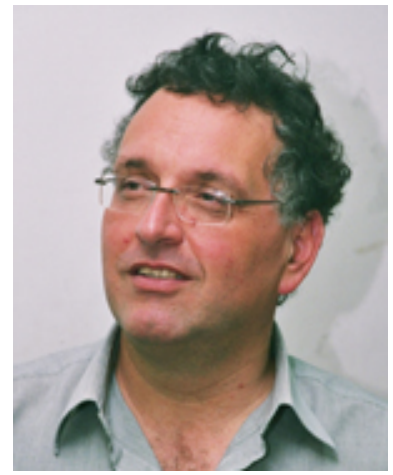

Rafi Nachmias is a Professor of Science Education at the School of Education of Tel Aviv University. He is currently heading the School of Education, the Science and Technology Education Center (SATEC) and the Virtual TAU project at Tel Aviv University. He has published over 100 papers and several books on the topic of ICT in Education. He is involved in several national and European research projects as principle researcher. 